\title{
WILL THE CURRENT AUTOMOTIVE INDUSTRY SURVIVE TO THE EMERGING MOBILITY ECOSYSTEM?
}

\author{
Ricardo Henrique da Silva, Prof. Dr. Paulo Carlos Kaminski \\ Universidade de São Paulo, Escola Politécnica \\ E-mails: ricardohsilva@usp.br, pckamins@usp.br
}

\begin{abstract}
With a new ecosystem of sustainable mobility emerging, a broad discussion has been taking place globally in the automotive industry on the evolution of transport and mobility. This debate is driven by the convergence of many forces and megatrends that can alter the structures of this industry. New social behaviors in relation to vehicle ownership and use as well as innovative technologies are changing the way companies develop and build their vehicles. Embedded digital technologies that can reduce human interference in the direction of the vehicle. New materials that reduce the weight of vehicles without impacting the safety of passengers. Electric and fuel cell propulsion systems deliver better energy efficiency and lower emissions when compared to current propulsion systems. The big question is whether the automotive industry will be a protagonist or supporting agent in the emergence and formation of this new ecosystem. It will evolve incrementally or if the change will occur at a more radical pace and be led by car manufacturers. No one knows the full scope or magnitude of the changes that are to come, but it is up to the present industry to react, and the first step in this direction is to understand the possible scenarios that these changes may bring. This work is descriptive and exploratory and is devoted to evaluating the main reports issued by consulting firms and even entities related to the automotive industry to shed light on what may happen with this industry within the emerging ecosystem to which it belongs. The great objective is that this material will be of value to researchers and decision makers within the automotive sector helping them to build their strategic plans and especially their innovation plans.
\end{abstract}

\section{INTRODUCTION: THE MOBILITY ECOSYSTEM}

Currently the concept of Innovation Ecosystems has been the guideline of many studies, both within academia in the areas of entrepreneurship, business administration as well as within the public policy agenda. Moore [9] suggested that firms are part of a business ecosystem that traverses a variety of industries in which companies co-evolve their capabilities around an innovation project. For him, there are four evolutionary stages of a business ecosystem: birth, expansion, leadership, and self-renewal. 
Adner [1] considered the business ecosystem as an ecosystem of innovation, which can be described in collaborative arrangements whereby firms combine their individual offerings into a coherent, customer-focused solution.

Nambisan and Baron [10] have suggested that the literature presents a number of ecosystem types of innovation, such as "ecosystem based on hubs, open source communities, research and development (R \& D) consortium, crowdsourcing ecosystem, etc. More recently Russel and Smorodinskaya [11] have stated that in many countries new, innovative and technologybased developments are increasingly encountering hierarchical barriers built by institutional and political regimes of the past. According to the same authors, to meet this challenge, it is necessary to cultivate a more complex and exosystemic thinking among decision makers at all levels (government agencies, business management and new program managers, etc.), since everyone will benefit to adjust their strategies and practices to new thinking.

Figure 1: The complexity of an ecosystem in a regional innovation cluster

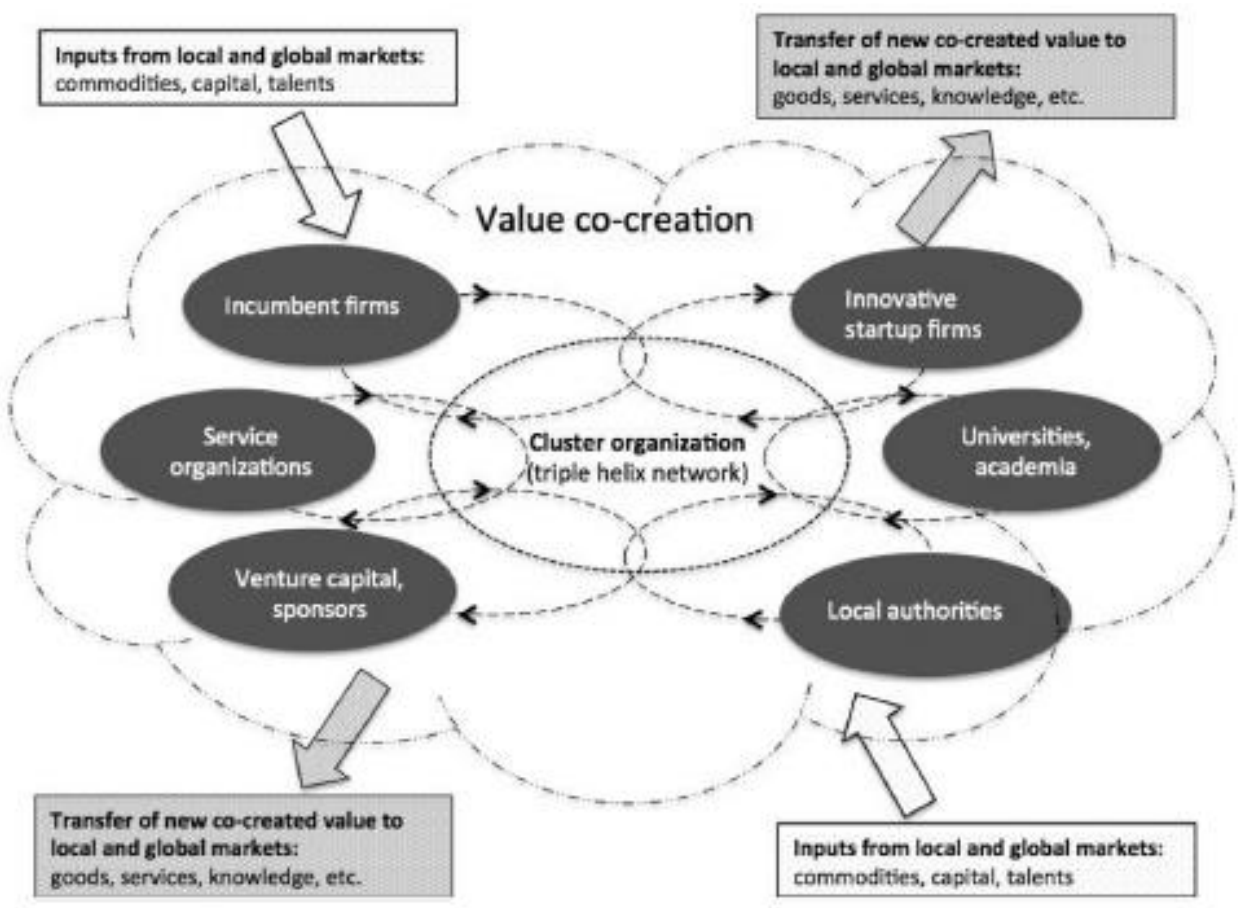

Source: extracted from Russel and Smorodinskaya (Leveraging complexity for ecosystemic innovation, 2018)

The current automotive industry is significant within the world economy and can be considered as part of an evolving but evolving ecosystem. The current ecosystem encompasses all elements involved in mobility (Figure 2) - includes not only vehicle assemblers who own most of the industry's turnover (as those in charge of producing and selling motor vehicles), but also includes financial agents which lend money, insurance companies, fuel suppliers, transport companies and services, public agents, etc. In the US alone, the expanded mobility system makes $\$ 2 \mathrm{~T}$ annually. 
Figure 2: 2014 US extended automotive industry revenue

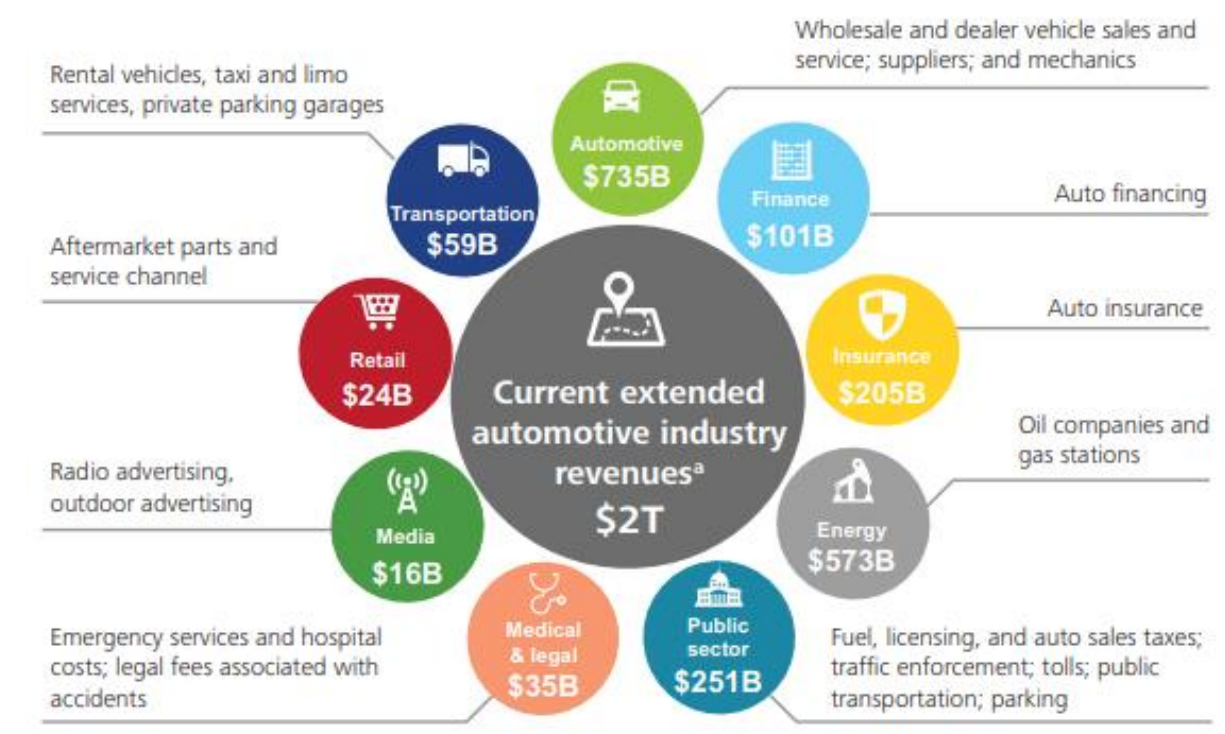

Source: Deloitte (How transportation technology and social trends are creating a new business ecosystem, 2015).

\section{AN EVOLVING ECOSYSTEM}

Ecosystems are dynamic systems that innovate, reinvent, and evolve as soon as recent technologies are brought aboard the existing ecosystem. In practice, any disturbance that changes the state of equilibrium of the current ecosystem, at the same time, forces the same to go in search of its new state of equilibrium (a state where all constituent elements of ecosystems act in a coordinated way and generate the value expected). Adner and Kapoor [2] deal with this theme and conclude, after analyzing 10 episodes of technological innovations in the semiconductor industry, that modern technologies are only successfully assimilated when the new ecosystem can assimilate them, and generate more value than it would generate in an ecosystem formed by a possible extension of the old technology.

Even with their significant importance and even playing a leading role within the expanded industry, automakers have become, over time, averse to disruptive innovations and have become dependent on a continuous improvement management system that is only a generator of only incremental innovations. The project management process itself is hardened by bureaucracies, documentation and tests that always seek maximum risk mitigation. Such a way of managing ends up barring innovative ideas from progressing and managing to survive the intense scrutiny of the innovation process in the industry. Vaz, Rauen and Lezana [14], after conducting a systematic review of the scientific literature in the Scopus database on sustainability and innovation between 2004 and 2016 in the field of industrial engineering of the global automotive sector, concluded that $97 \%$ of the articles found with incremental innovation and only $3 \%$ dealing with radical innovation. The authors concluded that this occurs once incremental innovations have lower risk, lower costs and less complexity. The 
author also highlights that the adoption of radical technology is rare because it requires major changes in skills and automotive operations.

\section{NEW ENTRANTS}

According to reports issued by consulting firms working in the global automotive industry, some direct consequences of this lack of radical innovations have caused the industry to be confronted by new entrants who threaten years of peace and relative success. Part of this historic success of automotive players has always depended on the attributes that their customers considered important such as aesthetics, power, comfort and brand. However, customers' perceptions of value are changing and future innovations will focus on disruptive technology trends that are increasingly putting automakers in a state of discomfort. According to the report by McKinsey [7] and by Deloitte [4], the trends that will favor new entrants are associated with developments that are happening within the following areas of research:

- Electrification: The car's propulsion system will shift to hybrid electric, electric and fuel cell technologies as they mature and become cheaper - in this field OEMs will continue to exercise dominance;

- Autonomous driving: automated car operation will shift from advanced self-service systems to fully autonomous steering as technology matures - in this field OEMs are losing room for technology industries;

- Sharing: As the sharing economy expands and consumer preferences change, the default model will continue to evolve from a definitive purchase or rent to car rentals and sharing - in this field the OEMs are losing room for the technology industry;

- Connectivity: The possibilities for infotainment innovations, new traffic services and new business models and services will increase as cars connect to each other, with infrastructure as well as pedestrians - here too OEMs are losing their race for the mobility industries.

Attracted by changing customer preferences, the importance of latest trends and the potential for value creation in the global automotive market, technology companies are entering and challenging the existing system. According to the same report by McKinsey [7], as technology companies advance in the development of new software, more cars are evolving into "[...]true on-wheeled computers, a similar shift to industry events of computers for 20 years and the handset industry 10 years ago. "As a result, there is a complex and intricate ecosystem emerging on the horizon that has the potential to take over the current global automotive industry (Figure 3). 
Figure 3: Cars becoming computer on wheels

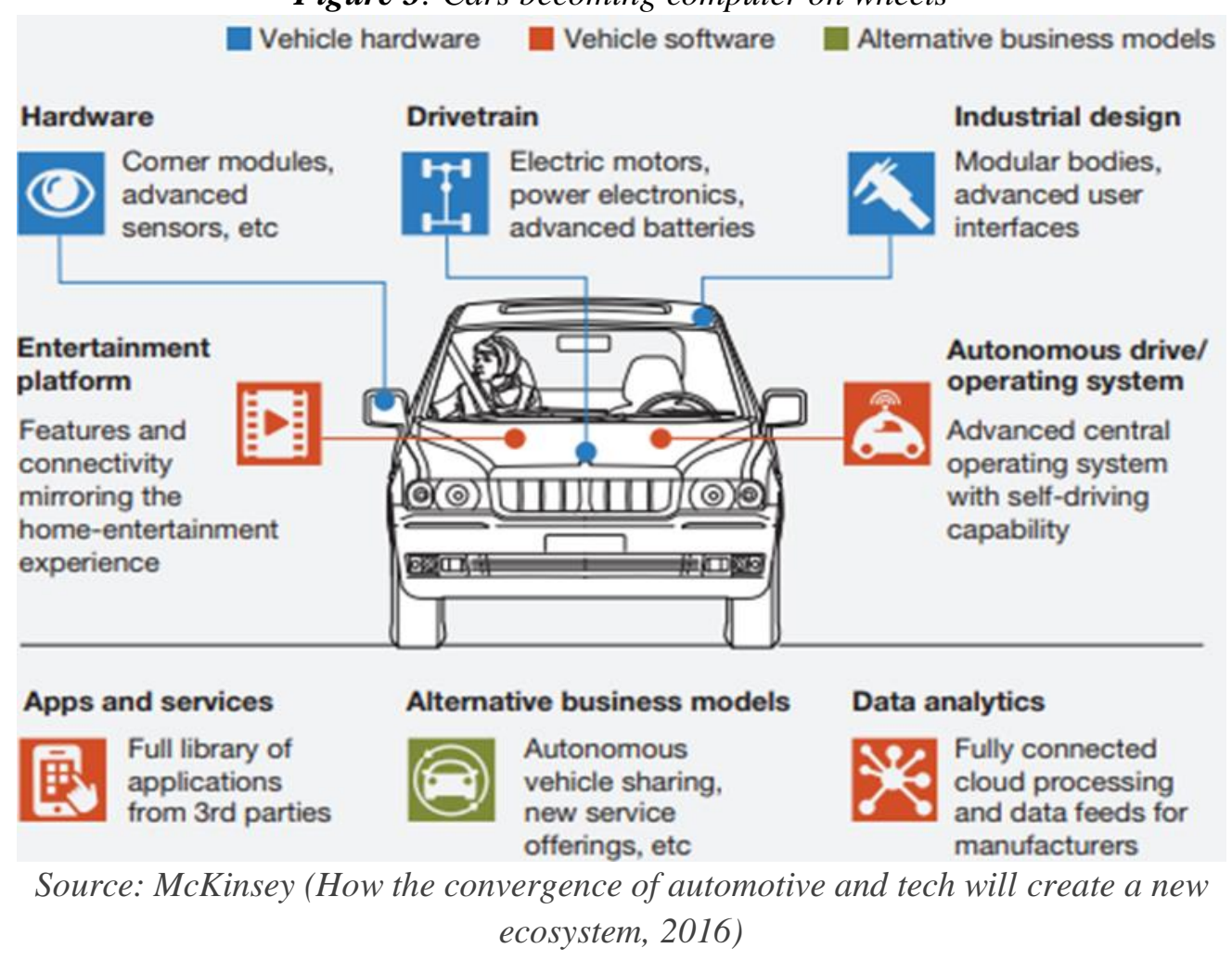

According to reports from consulting firms Deloitte [4] and KPMG [6], when considering the disparate forces shaping the new ecosystem at birth, four potential future scenarios of personal mobility may emerge if critical trends as shown in Figure 4:

- Vehicle control (driver versus autonomous);

- Vehicle ownership (private versus shared).

As Figure 4 indicates, state 1 predicts that private property will remain the norm, with consumers opting for the traditional forms of privacy, flexibility, safety, and convenience brought about by vehicle ownership. Although it incorporates autonomous steering technologies, this state assumes that the fully autonomous direction will not become widely available in a brief time (at least not until 2030).

Scenario 2 is one where passengers will value more the convenience of 'point-to-point' transportation created through car sharing and ridesharing due to the hassle of driving on streets and avenues with congested traffic and parking spaces. In addition, the system will offer options for non-drivers, such as seniors, low-income families and unlicensed minors. As in state 1 , in this possible scenario, fully autonomous cars would still be a reality not so close.

State 3 is one in which technologies to make autonomous vehicles prove to be viable, secure, convenient, and economical, yet private property remains the rule for social behavior rather than possession and benefits thereof. 
Figure 4: Future states of mobility
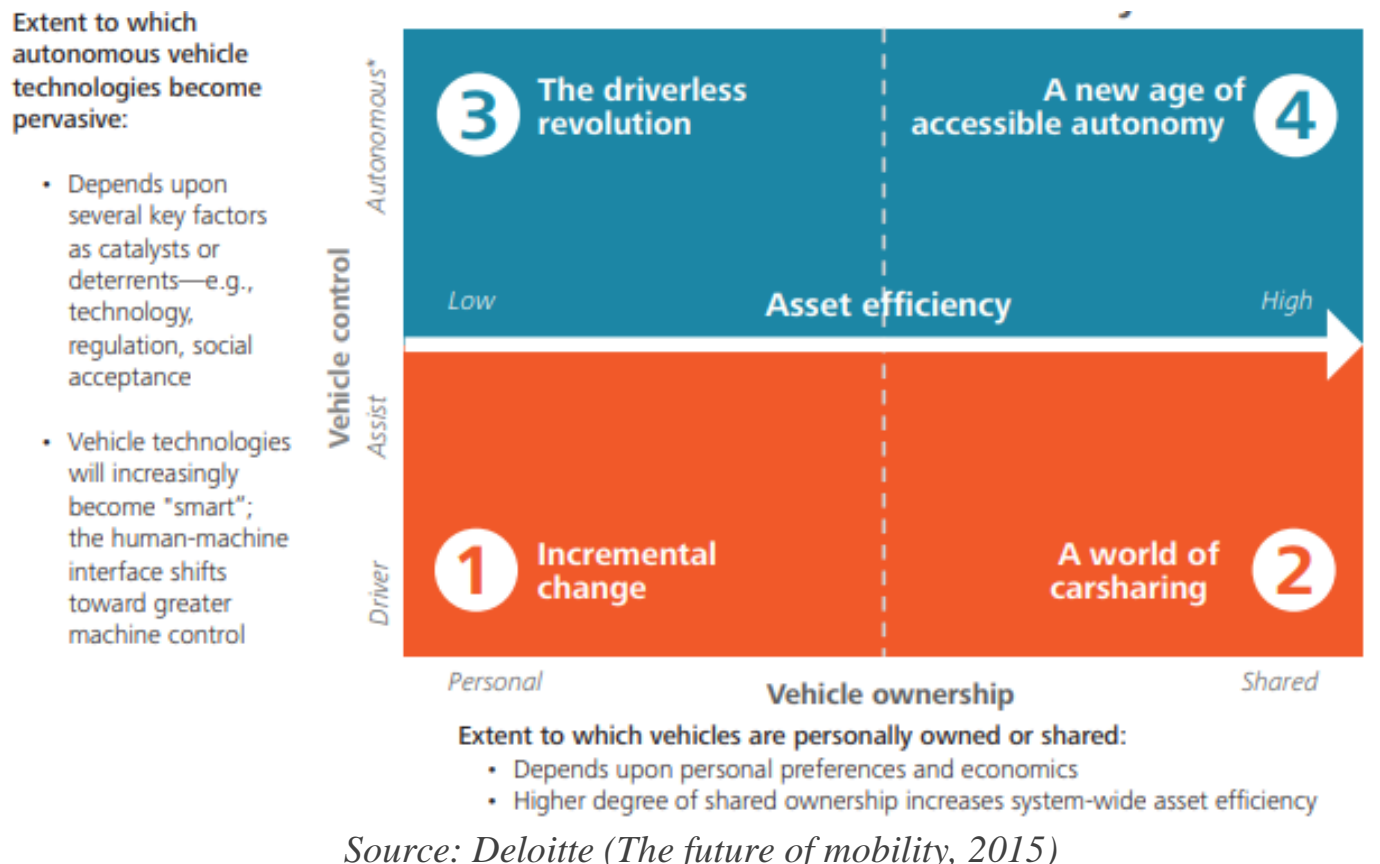

The fourth and final probable future state is one in which the convergence of the totally autonomous direction and vehicle sharing convergence occurs. In this scenario, over time, intelligent infrastructure expands from the urban centers to the densely populated suburbs. In addition, there will be advanced communication technologies and will coordinate users' pointto-point mobility experience (Figure 5). There will be intuitive digital interfaces that will allow users to request a vehicle in minutes and travel from point $\mathrm{A}$ to point $\mathrm{B}$ in an efficient, safe and economical way.

In this scenario, with fully autonomous and shared vehicles, mobility would proliferate, opening opportunities for companies that seek to sell content, entertainment and experience, improving the quality of time spent in traffic. The safe and efficient movement of people and goods would depend critically on available infrastructure, underscoring the key role played by suppliers of physical infrastructures and energy infrastructures. Transit stations, streets, avenues, highways, waterways and public parking would become even more interconnected, as customers increasingly seek multimodal transportation. This means providing:

- Intelligent toll pricing and dynamic road use;

- $\quad$ Real-time traffic flow management;

- Seamless connectivity that keeps customers online, regardless of time, location or mode of travel;

- A horizontal operating system that is shared by all participants across the ecosystem;

- Network security that protects customer data and the overall mobility system. 
Figure 5: The future of mobility ecosystem

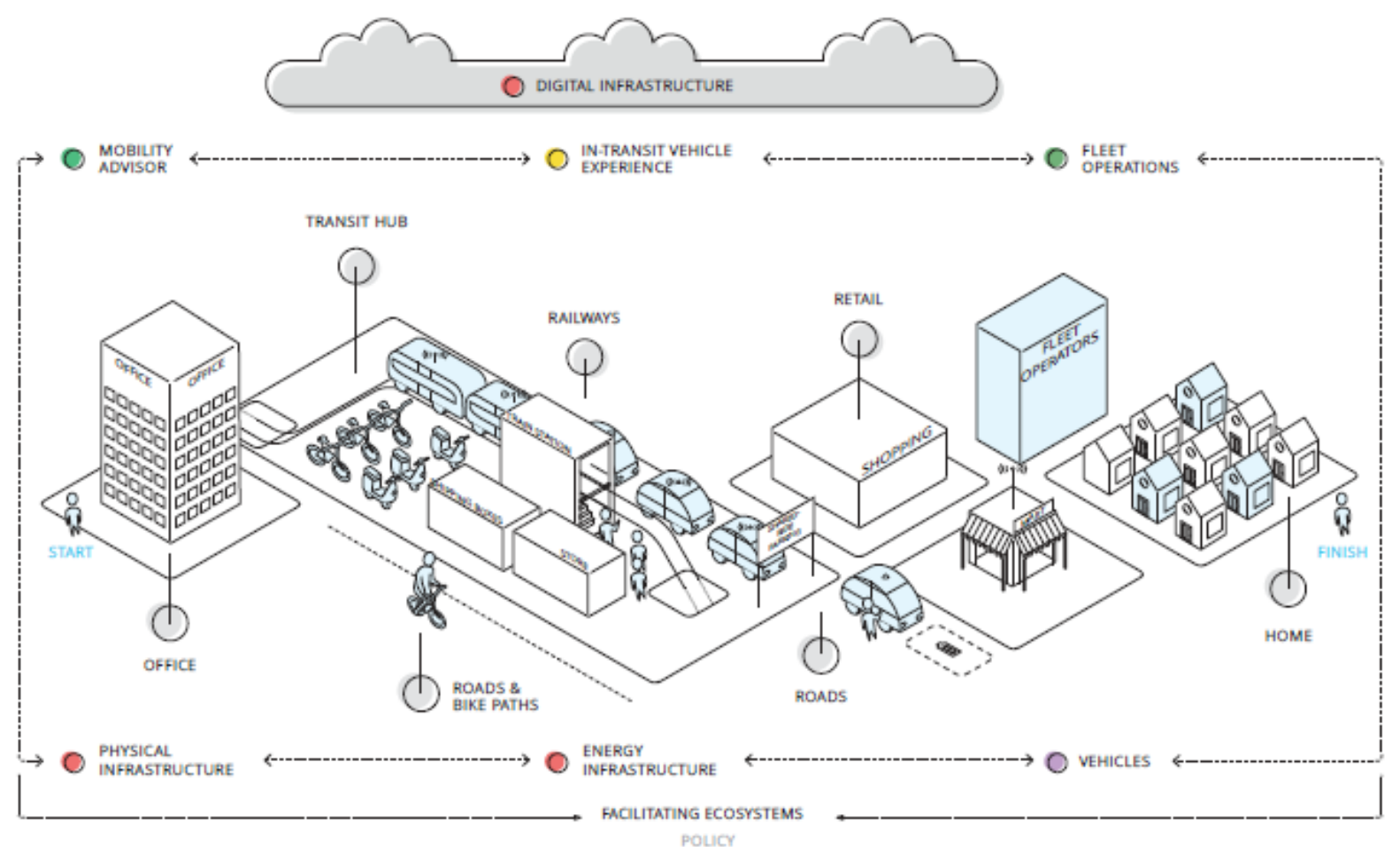

PRICING, PAYMENTS, AND INSURANCE

Source: Deloitte (How can European automakers thrive in the new mobility ecosystem)

A recent report from the McKinsey [8], presents scenario 4 of Figure 4 as being the most likely and next to occur. The report demonstrates that autonomous driving, connected cars, electrification and smart mobility - made significant strides in 2018 "[...]was the year in which theoretical discussions about the future of mobility became concrete actions in companies, cities and major regions of the world "mentions the report based on the following:

1. The pace of global investment in future mobility technologies is accelerating strongly: between the periods 2010-2013 and 2014-2017, average annual investment in all technologies jumped almost six-fold to $\$ 25.3$ billion per year, of US $\$ 4.3$ billion per year;

2. Software's account for $10 \%$ of total vehicle content currently for a D-segment car (approximately US $\$ 1,220$ ), and average software participation is expected to grow at a compound annual rate of $11 \%$ to reach $30 \%$ of total vehicle content (about $\$ 5,200$ ) in 2030;

3. Growth in the use of Artificial Intelligence (IA) added to the vehicle - and the technologies of autonomous direction;

4. Cities are beginning to use in their master plans the concept of 'Smart Cities' in the creation of legislation and public policies.

Theoto [13] et al., concluded in her paper that there are already countries moving quickly to what would be a quick adoption of autonomous and shared cars without even a way back. They are countries that, in addition to being ahead in research and development, have 
populations that are less resistant to new mobility technologies and, therefore, with a favorable behavior of adopting fully autonomous and shared vehicles. They are countries that add two other characteristics that are fundamental in this new emerging ecosystem:

- Favorable and flexible public policies and legislation;

- Costs of ownership and maintenance of vehicles.

Within this context of the emergence of a new ecosystem of what could be called sustainable mobility, is the rapid insertion and growth of the domain of these new entrants from the technology industry. A report from Deloitte [5] shows that the power balance will be as described in Figure 6 depending on the final state of this new ecosystem. In this analysis, the best scenario for OEMs is that they lead and be protagonists of this digital revolution within the mobility ecosystem.

Figure 6: four scenarios for the European OEM in 2025

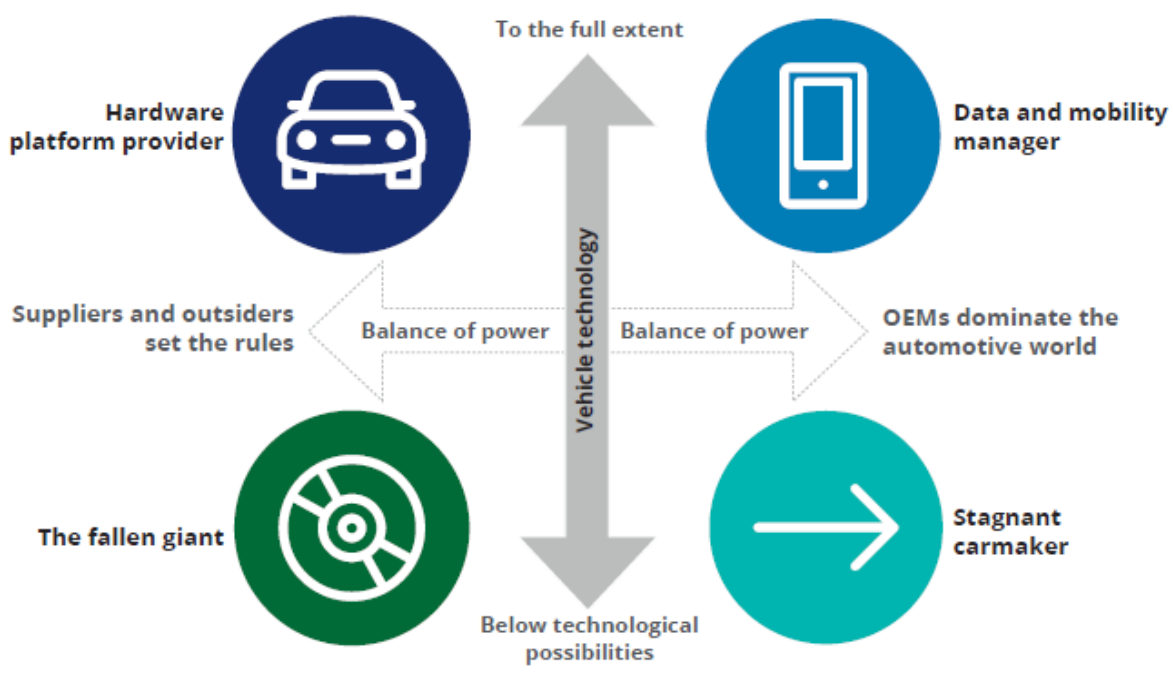

Source: Deloitte (How can European automakers thrive in the new mobility ecosystem, 2018)

A study made by McKinsey [7] also shows that tech companies have the financial and human capital advantage to face automakers in the new emerging ecosystem. Financial because these companies have enjoyed healthier cash flows for some years already, and human capital because they also have engineers prepared for this digital revolution that is changing the whole mobility ecosystem.

\section{CONCLUSION}

For all the reasons presented in this research work is that new researches should be developed to provide vehicle assemblers and their supplier, strategies and alternatives so that they can enter this fight for the hegemony of a new mobility ecosystem that has been emerging in the horizon. It is time for the them to get out of their comfort zone and make the necessary 
strategic adjustments to face the new tech companies that are entering to stay or even lead the journey ahead.

\section{REFERENCES}

[1] Adner, R., 2006. Match your innovation strategy to your innovation ecosystem. Harv. Bus. Rev. 84 (4), 98-107.

[2] Adner, R., Kapoor, R., 2016. Innovation ecosystems and the pace of substitution: Reexamining technology S-curves. Strategic Manager Journal. 37 (4).

[3] Deloitte, 2015. How transportation technology and social trends are creating a new business ecosystem.

[4] Deloitte, 2015. The Future of Mobility

[5] Deloitte, 2018. How can European automakers thrive in the new mobility ecosystem?

[6] KPMG, 2018. Global Automotive Executive Survey

[7] McKinsey, 2016. How the convergence of automotive and tech will create a new ecosystem.

[8] McKinsey, 2018. Reserve a seat - the future of mobility is arriving early.

[9] Moore, J.F., 1993. Predators and prey: a new ecology of competition. Harv. Bus. Rev. 71 (3), 75-86.

[10] Nambisan, S., Baron, R.A., 2013. Entrepreneurship in innovation ecosystems: Entrepreneurs' self-regulatory processes and their implications for new venture success. Enterp. Theory Pract. 37 (5).

[11] Russell, M.G., Smorodinskayab, N.V., 2018. Leveraging complexity for ecosystemic innovation. Technological Forecasting \& Social Change. 136 (11), 114-13.

[12] Smorodinskaya, N.V., 2017. Innovation ecosystems vs. innovation systems in terms of collaboration and co-creation of value. Proceedings of the 50th Hawaii International Conference on System Sciences | 2017

[13] Stadler, S., Cornet, H., Theoto, T. N., Frenkler, F., 2019. A Tool, not a Toy: Using Virtual Reality to Evaluate the Communication Between Autonomous Vehicles and Pedestrians Augmented Reality and Virtual Reality. Springer Nature Switzerland AG

[14] Vaz, C.R., Rauen, T.R.S., Rojas, Lezana, A.G.R., 2017. Sustainability and innovation in the automotive sector: A structured content analysis. MDPI. 23 May 2017. Basel, Switzerland 